\title{
1 Freshwater shrimp (Palaemonetes australis) as a potential bioindicator of crustacean health
}

2

3

4 Diane $\mathrm{Webb}^{1} *$

5

$6 \quad{ }^{1}$ Curtin University of Technology, Department of Environmental and Agriculture, Kent Street, Bentley WA 7 6102, Australia

8

9
*Corresponding author: Tel: +61 89266 2513; Fax: +61 89266 2495; email: d.webb@curtin.edu.au 


\section{Introduction}

33 Crustaceans are important inhabitants in aquatic ecosystems providing many ecological and economic

34 benefits and occupying diverse niches. For example, grass shrimp (Palaemonetes pugio) function to

35 repackage detritus into protein rich products that are used within different trophic levels in an ecosystem.

36 Welsh (1975) has shown that P. pugio plays an active role in breaking down detritus, enabling accelerated

37 growth rates of diatoms and bacteria on substrata in tidal march ecosystems.

39 Recently endocrine disruption has been reported in several decapod species (crabs, shrimps, prawns, etc;

40 (LeBlanc 2007). Many are dioecious with strong sexual dimorphism making decapods ideal field monitoring

41 candidates for the presence of endocrine disrupting chemicals. Urban and agricultural use of land adjacent to

42 estuaries and their tributaries have been shown to increase the potential for contaminant influx to the

43 environment through non point-source runoff. Pesticide usage near estuarine systems, polycyclic aromatic

44 hydrocarbons (PAHs) and heavy metals in stormwater inputs have been shown to impact on grass shrimp

45 (Palaemonetes spp.) growth, size, reproductive capacity and survival (Oberdorster et al. 2000b; Leight et al.

46 2005).

47

48 The hepatopancreas is the main organ for digestion and xenobiotic detoxification in aquatic invertebrates.

49 This organ is very responsive to environmental changes (Sousa and Petriella 2007; Snyder 2000). The PAH,

50 pyrene, has been shown to significantly induce CYP1A-like protein activity in P. pugio as measured by

51 ethoxycoumarin-O-deethylase (ECOD) in crude hepatopancreatic extracts. Studies by Lee et al. $(2008 ; 2004)$

52 have shown a relationship between reproductive abnormalities and increased DNA strand breaks when $P$.

53 pugio were exposed to estuarine sediments receiving highway runoff.

55 There is the potential that similar factors are affecting the health of crustaceans in the Swan-Canning Estuary,

56 south-west Western Australia. A three year program to study contaminant levels in both the Swan and

57 Canning Rivers, and their catchment drains, by the Western Australian Department of Water has shown that

58 organochlorine pesticides, PAHs, herbicides, and heavy metals are present in stormwater drains and

59 tributaries that discharge to the estuary (Foulsham et al. 2009; Nice et al. 2009; Nice 2009). For example, 
61 reported, in the range of 0.005 to $0.05 \mathrm{mg} / \mathrm{kg}$.

62

63 The freshwater shrimp Palaemonetes australis is a euryhaline crustacean found in relative abundance

64 throughout the estuary and its catchment drains and tributaries (Boulton and Knott 1984). This species has

65 not previously been assessed for its potential use as a bioindicator species in environmental monitoring

66 programs using biochemical markers of health. The objective of this study is to evaluate a selection of

67 biochemical markers of health in $P$. australis [ethoxycoumarin-O-deethylase activity (ECOD); sorbitol dehydrogenase activity (SDH); and DNA nucleoside base concentration (8-hydroxy-2'-deoxyguanosine)] by exposing the shrimp to a known genotoxicant, benzo[a]pyrene, under laboratory conditions. The value of $P$. australis as a suitable bioindicator species to understand the impact of organic chemicals on crustaceans within estuarine environments such as the Swan-Canning Estuary will be assessed.

\section{Materials and methods}

Adult Palaemonetes australis were collected by dip nets in April 2009 from the Canning River, Western Australia $(N=100)$. The shrimp were carefully placed in 20 litre buckets with water from the collection site for transport to the laboratory. Gentle aeration was provided using battery operated aerators with airstones attached. The shrimp were randomly allocated to one of twenty, $3 \mathrm{~L}$ Pyrex beakers to give a final count of 5 shrimp per beaker. The beakers had been filled with 2 litre of river water separately collected at the same

82 time as the shrimp and aerated gently. The shrimp were acclimated to laboratory conditions for 10 days

83 during which time up to $50 \%$ water changes were performed daily to remove wastes using Millipore filtered

84 water adjusted to 3 ppt salinity. Ammonia levels were monitored daily and the shrimp were fed with frozen 85 Artemia until sated. 
89 At the end of the acclimation period the beakers were allocated to one of 5 treatment groups using a

90 randomised block design. Ten $\mathrm{mg}$ of benzo $[a]$ pyrene $(\mathrm{B}[a] \mathrm{P})$ was dissolved in $10 \mathrm{~mL}$ of dimethyl sulphoxide

91 (DMSO), then $2 \mathrm{~mL}$ of this solution was diluted in $198 \mathrm{~mL} \mathrm{50 \%} \mathrm{DMSO} / \mathrm{H}_{2} \mathrm{O}$. Three subsets of 4 beakers

92 were treated with the diluted solution to give concentrations of $0.01 \mathrm{ppm}, 0.1 \mathrm{ppm}$ and $1 \mathrm{ppm}$ of $\mathrm{B}[a] \mathrm{P}$

93 respectively. A $50 \%$ solution of $\mathrm{DMSO} / \mathrm{H}_{2} \mathrm{O}$ was added to a fourth subset of 4 beakers to give a final

94 concentration of $0.0005 \%$ (solvent control group). The final subset of 4 beakers was left untreated as the

95 negative control group. The exposure concentrations of $\mathrm{B}[a] \mathrm{P}$ used in this study were chosen to ensure a

96 measurable response from the shrimp and do not reflect the level of this contaminant in the field.

97

98 Shrimp were continuously exposed for a period of 14 days during which time the daily $50 \%$ water change

99 regime was continued with chemical levels within each exposure group maintained by replacement. At the

100 end of the exposure period the shrimp were anaesthetised in an ice and water slurry. The tail fan, legs and

101 exoskeleton were removed from each shrimp before the abdomen was separated from the cephalothorax. The

102 abdominal muscle was placed in a cryovial for sorbitol dehydrogenase determination and the cephalothorax

103 was placed in a separate cryovial for ethoxycoumarin O-deethylase and 8-hydroxy-2'-deoxyguanosine

104 assays. Each cryovial was immediately immersed in liquid nitrogen, then later transferred to a freezer and

105 held at $-80{ }^{\circ} \mathrm{C}$ until analysis.

106

107 Supernatant Preparation

108

109 A homogenisation buffer was prepared containing $0.1 \mathrm{M}$ Trizma (tris hydroxymethyl aminomethane) base,

$11025 \mathrm{mM}$ phenylmethanesulphonyl fluoride (PMSF) and $1.3 \mathrm{mM}$ ethylenediaminetetraacetic acid (EDTA) with

$111 \mathrm{pH}$ adjusted to $\mathrm{pH}$ 7.4. Samples were thawed on ice and homogenised in the buffer (shrimp tail 1:2 w/v;

112 cephalothorax 1:4 w/v) using a Heidolph DIAX 900 homogeniser. The homogenate was centrifuged (Jouan

113 CR3i centrifuge) at $9000 x g$ for 20 mins at $4^{\circ} \mathrm{C}$ and the supernatant collected for immediate use. Protein

114 content of the cephalothorax supernatant was measured using the method of Lowry et al. (1951).

115

116 Ethoxycoumarin-O-deethylase (ECOD) Assay

117 
118 ECOD activity was assessed using the method of Webb et al. (2005), optimised for invertebrates. The

119 reaction mixture containing $0.1 \mathrm{M}$ Tris buffer $\mathrm{pH} 7.4, \mathrm{KCl}, \mathrm{MgCl}_{2}, \mathrm{NADPH}$ (ß-nicotinamide adenine

120 dinucleotide phosphate, reduced form) solution, and cephalothorax supernatant, was incubated for 2 minutes

121 in a water bath at $35^{\circ} \mathrm{C}$. The reaction was initiated by adding $2 \mathrm{mM}$ ethoxycoumarin, incubated for a further

12210 minutes at $35^{\circ} \mathrm{C}$ and then terminated by the addition of $5 \% \mathrm{ZnSO}_{4}$ and saturated $\mathrm{Ba}(\mathrm{OH})_{2}$. Umbelliferone

$123\left(\mathrm{C}_{9} \mathrm{H}_{6} \mathrm{O}_{3} ; 7\right.$-hydroxycoumarin $)$ standards $(0.000$ to $0.093 \mathrm{nM})$ and samples were centrifuged to precipitate

124 proteins and $1 \mathrm{~mL}$ of the supernatant was transferred to a test tube. $500 \mu \mathrm{L}$ of $0.5 \mathrm{M}$ glycine- $\mathrm{NaOH}$ buffer $\mathrm{pH}$

12510.4 was added to each tube and the fluorescence of the buffered supernatant was read on a Perkin-Elmer LS-

12645 Luminescence Spectrometer at excitation/emission wavelengths of 380/452 nm. ECOD activity was

127 expressed as femtomoles of 7-hydroxycoumarin produced, per mg of total protein, per minute (fmol $\mathrm{H} \mathrm{mg} \mathrm{Pr}^{-}$

$\left.128{ }^{1} \mathrm{~min}^{-1}\right)$.

129

130 Sorbitol Dehydrogenase (SDH) Assay

131

132 The SDH assay was adapted for abdominal muscle supernatant from Webb and Gagnon (2007) methods. A

$13350 \mu \mathrm{L}$ aliquot of supernatant was placed in a cuvette with $450 \mu \mathrm{L}$ of $\beta-\mathrm{NADH}$ (ß-nicotinamide adenine

134 dinucleotide, reduced form) - Tris Buffer, $\mathrm{pH}$ 7.5, solution. This was then incubated at room temperature for

13510 minutes to allow for the reaction of keto acids in the serum. Following incubation, $100 \mu \mathrm{L}$ of D-Fructose

136 solution was added to commence the reaction and the decrease in the rate of absorbance $(\Delta \mathrm{A})$ over one

137 minute was immediately read on a Pharmacia UV-Visible Spectrophotometer at $340 \mathrm{~nm}$. The SDH activity

138 was expressed as milli-International Units $(\mathrm{mU})$ in the abdominal supernatant of the shrimp.

139

140 8-hydroxy-2'-deoxyguanosine (8-oxo-dG) Quantification

141

142 The 8-oxo-dG assay was performed on clarified cephalothorax supernatant using an enzyme immunoassay

143 (EIA) kit (Trevigen ${ }^{\circledR}$ Cat. No. 4370-096-K; purchased from BioScientific Pty Ltd, NSW, Australia). Sample

144 preparation was performed as recommended for saliva samples then diluted 1:10 v/v in sample diluent.

145 Leaving the first two wells blank, $50 \mu \mathrm{L}$ of 8 -oxo-dG Standard ( 0 to $60 \mathrm{ng} / \mathrm{mL}$ ), and diluted samples were

146 added to the appropriate wells of the immunoassay plate in duplicate. $50 \mu \mathrm{L}$ of anti-8-oxo-dG antibody was

147 added to each well (except the blanks) then incubated at room temperature for 1 hour. The wells were 
aspirated and washed 6 times using a Immunowash model 1575 (Bio-Rad Laboratories Pty Ltd, NSW,

149 Australia), patted dry, then $100 \mu \mathrm{L}$ Anti-Mouse IdG:HSP conjugate antibody added to each well (blanks

150 excluded) and incubated for 1 hour at room temperature. Following a further 6 washes, $100 \mu \mathrm{L}$ TMB

151 Substrate (stabilised tetramethylbenzidine) was added to all wells, incubated in the dark for 15 minutes, then

$152100 \mu \mathrm{L}$ Stop Solution added to each well. Absorbance of the wells was measured at $450 \mathrm{~nm}$ using a Bio-Rad

153 iMark Microplate Reader (ISO 9001 registered). The average of the absorbance of the duplicate blank wells

154 was deducted from the average of the standard and the sample wells. Plotting the standard curve with log

155 concentrations on the $\mathrm{x}$-axis and absorbance measurements for the respective standards on the $\mathrm{y}$-axis gave a

$1562^{\text {nd }}$ order polynominal equation $y=a+b x+\mathrm{cx}^{2}$. The 8-oxo-dG concentration in the supernatant was

157 expressed as nanograms of 8-hydroxy-2'-deoxyguanosine, per mg of total protein (ng 8-oxo-dG mg $\operatorname{Pr}^{-1}$ ).

Statistical Analysis

160

161 For each biomarker, the data were tested for normality and homoscedasticity and, where necessary, $\log _{10^{-}}$ 162 transformed to achieve normality. Statistical analysis was undertaken using the SPSS statistical package 163 (Version 17; SPSS GmbH, Germany). Student t tests found no gender difference for each biomarker ( $p>$ 164 0.05), so data for was pooled. A two-way analysis of variance (ANOVA) was run to investigate if the data was affected by beaker/replicate interactions. As no interactions were found in the data sets, main effects

166 were analysed using one-way ANOVAs. Where significant differences between treatments were found ( $p<$ 167 0.05), a Dunnett's (2 sided) test was run to compare the treatment groups with the negative control group.

168 Data are presented as mean \pm standard error (SEM).

\section{$170 \quad$ Results}

172 Ethoxycoumarin-O-deethylase Activity

174 Significant induction of ECOD activity occurred in all treatment groups $(p \leq 0.001)$. There was no significant 175 difference between the negative control and solvent control groups $(p=0.22)$. ECOD activity in the $0.01 \mathrm{ppm}$ treatment group was $220 \%$ higher than the level of the negative control group while the $0.1 \mathrm{ppm}$ and $1 \mathrm{ppm}$ 


\section{8 (Fig. 1).}

182 No significant differences were detected in SDH activity in $P$. australis between any treatment group ( $p=$ 183 0.29; Fig. 2).

184

8-hydroxy-2'-deoxyguanosine Concentration

The concentration of 8-oxo-dG measured in the freshwater shrimp was significantly different between treatment groups $(p=0.003)$. There was no significant difference between the negative control and solvent control groups $(p=0.80)$. The three treatment groups each had $66 \%$ lower concentration of 8 -oxo-dG than the negative control treatment groups and 54\% lower than the solvent control group (Fig.3).

\section{Discussion}

193

194 Shrimps, such as P. australis, are key links in the estuarine detritus food web. The Swan and Canning Rivers

195 and their catchment drains are known to receive anthropogenic contaminants (Foulsham et al. 2009; Nice

196 2009; Nice et al. 2009) that may adversely affect this ecologically important animal. Although the life cycle

197 of P. australis has been poorly studied in estuaries of south-west Western Australia, this study found it to be 198 easily maintained in the laboratory, making it an ideal candidate for the study of the impact of contaminant 199 exposure on the health of this estuarine decapod species.

PAHs have been shown to significantly induce CYP1A-like protein (P450) activity in grass shrimp ( $P$.

203 elsewhere have indicated that blue crabs (Callinectes sapidus) were unable to metabolise and eliminate PAHs

204 the closer they were to moulting, resulting in a higher body burden (Mothershead and Hale 1992). PAHs

205 have also been shown to delay moulting by P. pugio males (Oberdorster et al. 2000a), and the blue crab

206 (Mothershead and Hale 1992). This is believed to be due to competition for substrates by cytochrome P450s 
needed to metabolise ecdysone for the moult (Mothershead and Hale 1992; Oberdorster et al. 2000a). In our study, P. australis exposed to $0.01,0.1$ and $1 \mathrm{ppm} \mathrm{B}[a] \mathrm{P}$, had a significantly elevated ECOD activity which

209 increased with each concentration of $\mathrm{B}[a] \mathrm{P}$. This clearly demonstrated that moulting was not a confounding

210 factor in the interpretation of the response of cytochrome P450 detoxification in the shrimp to B[a]P exposure

211 in this study. The shrimp clearly demonstrated increasing ECOD activity induction with increasing exposure

212 concentrations.

213

214 Gender differences have been found to occur in the uptake and elimination of contaminants in a range of 215 invertebrate species due to competition between moulting, reproduction, vitellin levels and P450 activity

216 (McClellan-Green et al. 2007). Gender specific induction of ECOD was detected by Oberdorster et al.

217 (2000a) in P. pugio when exposed to pyrene at $63 \mathrm{ppb}$. In that study, pyrene induced ECOD activity in males

218 only. It was hypothesised that the lack of induction of ECOD in the female shrimp was due to the maternal

219 transfer of the pyrene, bound to egg yolk proteins, to oocytes (Oberdorster et al. 2000a). Gender differences

220 in ECOD activity induction was not evident in P. australis exposed to $\mathrm{B}[a] \mathrm{P}$ in this study, however this

221 confounding factor needs to be considered when measuring ECOD activity in field captured P. australis by

222 ensuring sufficient numbers of each sex are collected for analysis and taking into account their stage in the

223 reproductive cycle.

224

225 Elevated sorbitol dehydrogenase (SDH) activity in abdominal muscle homogenate is an indicator that the

226 cellular integrity of the hepatopancreas has been compromised (Battison 2006). Sousa and Petriella (2007)

227 found important alterations in the hepatopancreas of $P$. argentinus exposed to high levels of organochlorine

228 pesticides including necrotic desquamation, lesions in the tubules, nuclear retraction, and lysis of the

229 chromatin and cytoplasm. A hepatopancreas with cellular injuries is less capable of detoxifying and

230 eliminating contaminants than a non-injured hepatopancreas and represents a further confounding factor

231 when interpreting ECOD activity supporting the parallel use of this marker of hepatopancreatic damage.

232 Furthermore, SDH activity precedes the detection of histological damage in the hepatopancreas and as such

233 monitoring changes in SDH activity can be a sensitive indicator of damage. The lack of inter-treatment

234 differences in SDH activity in this study indicates there is no bias in the ECOD activity measured related to

235 hepatopancreatic tissue damage. From the results of the laboratory exposure to $\mathrm{B}[a] \mathrm{P}$ in the negative control 
236 shrimp, a baseline level of $50 \mathrm{mU} \mathrm{mL}^{-1} \mathrm{SDH}$ in the abdominal muscle homogenate of P. australis is

237 established which can be used in field studies to determine whether hepatopancreatic damage has occurred.

239 The concentration of 8-oxo-dG indicates DNA damage by hydroxyl radicals and has been shown to be 240 induced by a range of environmental contaminants (Evans et al. 2004; Valavanidis et al. 2009). Oxidative

241 damage has been reported in both humans and fish species in response to heavy metals, peroxides,

242 antibiotics, PAHs, asbestos fibres, and tobacco smoke (Valavanidis et al. 2009; Livingstone 2001). Exposure

243 to $\mathrm{B}[a] \mathrm{P}$ resulted in a significant decrease in 8-oxo-dG concentrations in $P$. australis which appears to

244 contradict other studies in rat, hamster and human cancers (Kasai 1997), and aquatic organisms exposed to

245 heavy metals $(\mathrm{Cd}, \mathrm{Cu}, \mathrm{Fe})$, paraquat, peroxides and PAHs (Livingstone 2001). However a similar decrease

246 has been found in barramundi exposed to $\mathrm{B}[a] \mathrm{P}$ injections in our laboratory (Rawson in preparation). There

247 is some evidence to suggest there are two pathways for the removal of 8-oxo-dG adducts. Bases suffering

248 oxidative damage are preferentially repaired by enzymes of the BER (base excision repair) pathway (Loft et

249 al. 2008). If the BER pathway is compromised a NER (nucleotide excision repair) pathway exists for the removal of the 8-oxo-dG adduct resulting in an observed reduction the amount of free 8-oxo-dG in the

251 haemolymph. A study undertaken by Hook and Lee (2004) found that exposure of P. pugio embryos to B[a]P

252 produced complex lesions. The DNA strand breaks persisted and their level increased as these lesions were

253 repaired by the NER pathway, whereas repairs by the BER pathway resulted in reduction of strand breaks

254 when the embryos were exposed to cadmium. This suggests that $\mathrm{B}[a] \mathrm{P}$ causes persistent lesions with the

255 potential to increase transcriptional errors, mutagenesis and cell death (Mitchelmore and Chipman 1998).

256 From the results of the laboratory exposures a baseline level of $5 \mathrm{ng}$ 8-oxo-dG $\mathrm{mg} \mathrm{Pr}^{-1}$ is determined, which

257 can be used to evaluate field results.

258

259 DMSO is commonly used as a polar solvent of low toxicity and to preserve cells in tissue culture, however it

260 has been shown to produce adverse changes in rat hepatocytes (Shilkin et al. 1966), and to potentiate the

261 lethal effects of aromatic hydrocarbons such as benzene (Kocsis et al. 1975). DMSO has also been shown to

262 produce apoptotic degeneration in the developing CNS of mice (Hanslick et al. 2009). No change was

263 identified in SDH activity when compared to the negative controls suggesting that exposure to the low

264 concentration of DMSO $(0.0005 \%)$ used in this study has not damaged the hepatopancreas of the shrimp. The

265 shrimp appear to have had a slight response to DMSO, with ECOD activity induction marginally higher in 
266 the solvent control group compared to the negative control group and 8-oxo-dG concentration was lower.

267 However, this apparent reaction to DMSO is not sufficient to influence interpretation of biomarker responses

268 of the shrimp to the PAH, B[a]P.

269

$270 \quad$ P. australis has been shown to be responsive to organic contaminants and is a suitable bioindicator species

271 for laboratory studies and/or field monitoring to aid our understanding of the health of biota in the Swan-

272 Canning Estuary. Further investigation is required to assess the suitability of other biomarkers of health (e.g.

273 DNA strand breakage, ecdysteroid production, embryo survival and development, incidence of intersex and

274 others) in this crustacean.

275

276

277 Acknowledgments This study was supported by a Swan Canning Research and Innovation Program grant

278 from the Swan River Trust, Perth, Western Australia. Collection of animals was in accordance with

279 Department of Environment and Conservation licence SF006828. Special thanks are extended to Miss

280 Felicity Trend for her assistance with the laboratory work.

281 
284 Battison, A. (2006). Tissue distribution and hemolymph activity of six enzymes in the American lobster (Homarus americanus): potential markers of tissue injury. Journal of Shellfish Research, 25(2),

Boulton, A. J., \& Knott, B. (1984). Morphological and electrophoretic studies of the Palaemonidae (Crustacea) of the Perth Region, Western Australia. Australian Journal of Marine and Freshwater Research, 35, 769-783.

Evans, M. D., Dizdaroglu, M., \& Cooke, M. S. (2004). Oxidative DNA damage and disease: induction, repair and significance. Mutation Research, 567(1), 1-61. to highway runoff sediments and sediments with coal fly ash. Marine Environmental Research, 66(1), 164-165. 
312 Leight, A. K., Scott, G. I., Fulton, M. H., \& Daugomah, J. W. (2005). Long term monitoring of grass shrimp

313 Palaemonetes spp. population metrics at sites with agricultural runoff influences. Integrated

314 Comparative Biology, 45, 143-150.

315 Livingstone, D. R. (2001). Contaminant-stimulated reactive oxygen species production and oxidative damage

316 in aquatic organisms. Marine Pollution Bulletin, 42(8), 656-666.

317 Loft, S., Danielson, P. H., Mikkelsen, L., Risom, L., Forchhammer, L., \& Moller, P. (2008). Biomarkers of

318 oxidative damage to DNA and repair. Biochemical Society Transactions, 36, 1071-1076.

319 Lowry, O. H., Rosebrough, N. J., Farr, A. L., \& Randall, R. J. (1951). Protein measurement with the Folin

320 Phenol reagent. Journal of Biological Chemistry, 193, 265-275.

321 McClellan-Green, P., Romano, J., \& Oberdorster, E. (2007). Does gender really matter in contaminant

322 exposure? A case study using invertebrate models. Environmental Research, 104(1), 183-191.

323 Mitchelmore, C. L., \& Chipman, J. K. (1998). DNA strand breakage in aquatic organisms and the potential

324 value of the comet assay in environmental monitoring. Mutation Research/Genetic Toxicology and

$325 \quad$ Environmental Mutagenesis, 399, 135-147.

326 Mothershead, R. F., \& Hale, R. C. (1992). Influence of ecdysis on the accumulation of polycyclic aromatic

327 hydrocarbons in field exposed blue crabs (Callinectes sapidus). Marine Environmental Research,

328 33(2), 145- 156.

329 Nice, H. E. (2009). A baseline study of contaminants in the sediments of the Swan and Canning estuaries.

330 Water Science Technical Series Report No. 6. Perth, Western Australia. Department of Water.

331 http://www.water.wa.gov.au/PublicationsStore/first/83909.pdf. Accessed 30 March, 2009.

332 Nice, H. E., Grassi, M., Foulsham, G., Morgan, B., Evans, S. J., \& Robb, M. (2009). A baseline study of

333 contaminants in the Swan and Canning catchment drainage system. Water Science Technical Series

334 Report No. 3. Perth, Western Australia. Department of Water.

335 http://www.water.wa.gov.au/PublicationsStore/first/83919.pdf. Accessed 30 March, 2009.

336 Oberdorster, E., Brouwer, M., Hoexum-Brouwer, T., Manning, S., \& McLachlan, J. A. (2000a). Long-term

337 pyrene exposure of grass shrimp, Palaemonetes pugio, affects molting and reproduction of exposed

338 males and offspring of exposed females. Environmental Health Perspectives, 108(7), 641-646.

339 Oberdorster, E., Rice, C. D., \& Irwin, L. K. (2000b). Purification of vitellin from grass shrimp Palaemonetes

340 pugio, generation of monoclonal antibodies, and validation for the detection of lipvitellin in

341 crustacea. Comparative Biochemistry and Physiology C, 127, 199-207. 
342 Shilkin, K. B., Papadimitriou, J. M., \& Walters, M.-I. (1966). The effect of dimethyl sulphoxide on hepatic 343 cells of rats. Australian Journal of Experimental Biology and Medical Science, 44(5), 581-584.

344 Snyder, M. J. (2000). Cytochrome P450 enzymes in aquatic invertebrates: recent advances and future 345 directions. Aquatic Toxicology, 48, 529-547.

346 Sousa, L. G., \& Petriella, A. M. (2007). Functional morphology of the hepatopancreas of Palaemonetes 347 argentinus (Crustacea: Decapoda): influence of environmental pollution. Revista de Biología $348 \quad$ Tropical, 55, 79-86.

349 Valavanidis, A., Vlachogianni, T., \& Fiotakis, C. (2009). 8-hydroxy-2' -deoxyguanosine (8-OHdG): A 350 critical biomarker of oxidative stress and carcinogenesis. Journal of Environmental Science and Health C, 27(2), 120 - 139.

352 Webb, D., \& Gagnon, M. M. (2007). Serum sorbitol dehydrogenase activity as an indicator of chemically induced liver damage in black bream (Acanthopagrus butcheri). Environmental Bioindicators, 2(3),

355 Webb, D., Gagnon, M. M., \& Rose, T. (2005). Interannual variability in fish biomarkers in a contaminated temperate urban estuary. Ecotoxicology and Environmental Safety, 62(1), 53-65.

357 Welsh, B. L. (1975). The role of grass shrimp, Palaemonetes pugio, in a tidal marsh ecosystem. Ecology, 56(3), 513-530.

359

360

361 


\section{List of Figures}

363

364 Fig. 1 Ethoxycoumarin-O-deethylase activity induction in fmol $\mathrm{H} \mathrm{mg}^{-1} \min ^{-1}$ (mean $\pm \mathrm{SE}$ ) in the

365 freshwater shrimp (Palaemonetes australis) following exposure to benzo[a]pyrene. Treatment groups

366 significantly different from the negative control $(p<0.05)$ are denoted by an asterisk $(*)$

367

368 Fig. $2 \mathrm{SDH}$ activity $\left(\mathrm{mU} \mathrm{mL}^{-1}\right.$; mean $\left.\pm \mathrm{SEM}\right)$ in the abdominal muscle supernatant of the freshwater shrimp

369 (Palaemonetes australis) following exposure to benzo[a]pyrene. Treatment groups significantly different

370 from the negative control $(p<0.05)$ are denoted by *

371

372 Fig. 3 8-hydroxy-2'-deoxyguanosine concentration in ng 8-oxo-dG $\mathrm{mg} \mathrm{Pr}^{-1}$ (mean $\pm \mathrm{SE}$ ) in the freshwater

373 shrimp (Palaemonetes australis) following exposure to benzo[a]pyrene. Treatment groups significantly

374 different from the negative control $(p<0.05)$ are denoted by *

375 


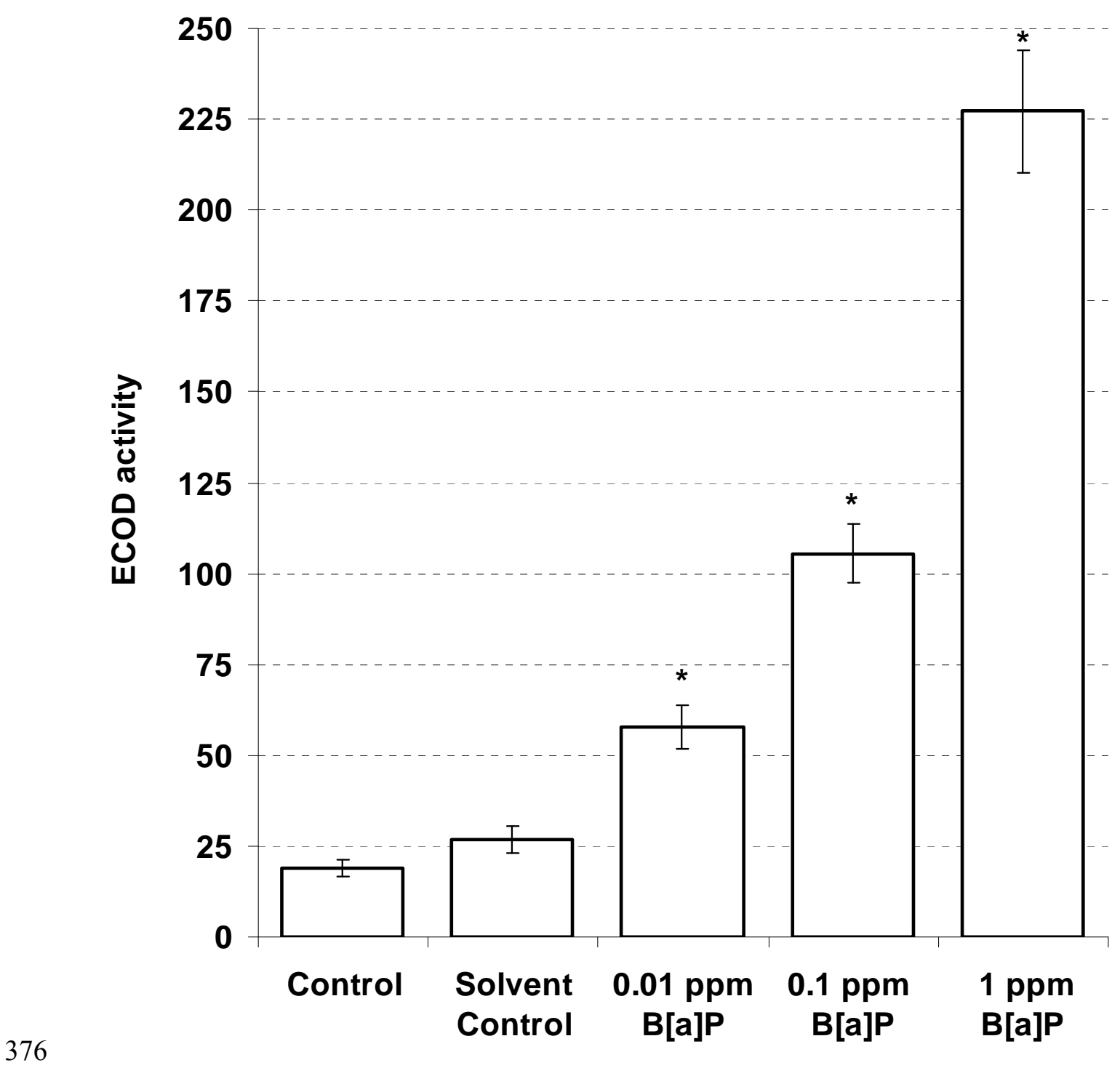




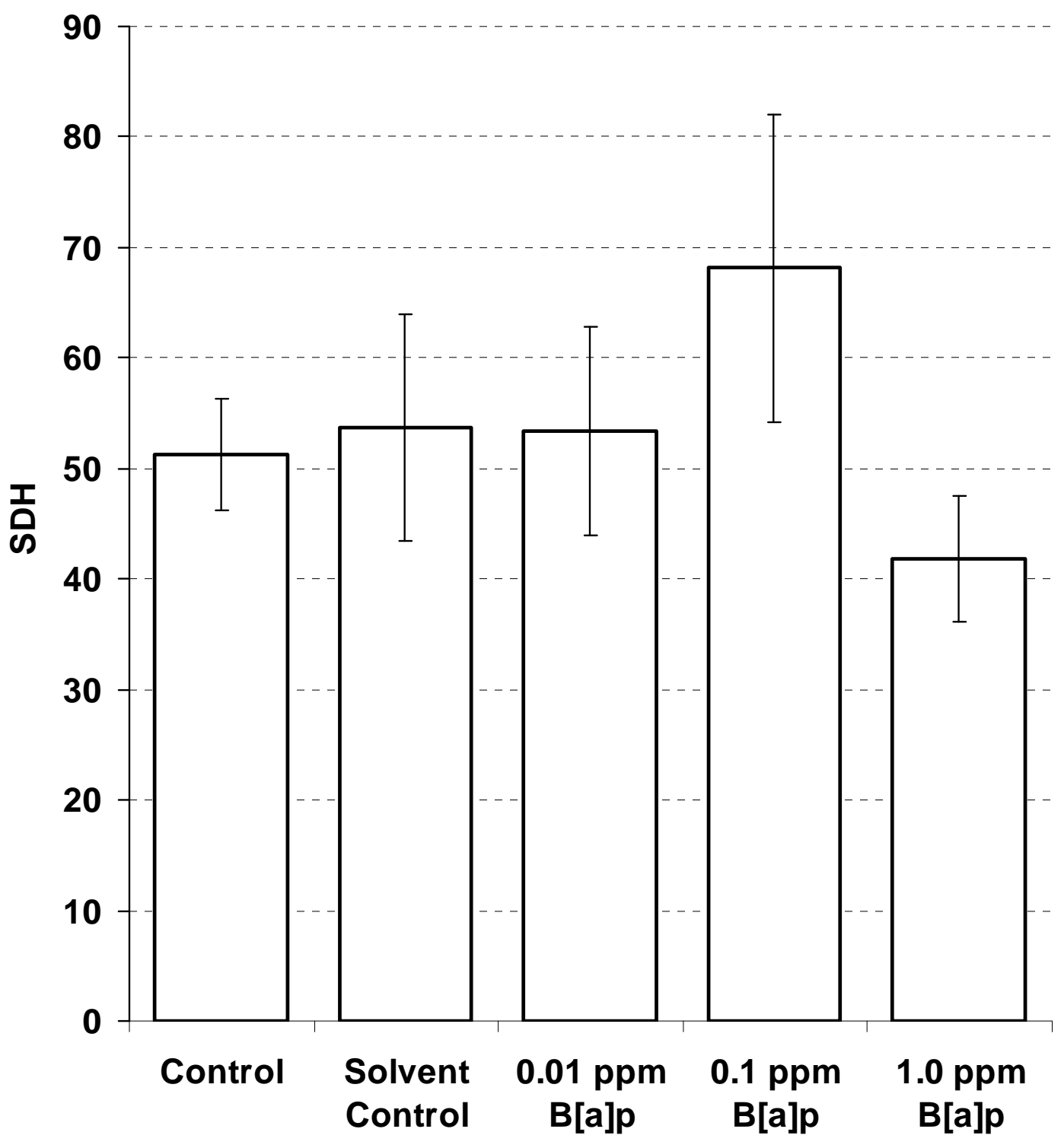




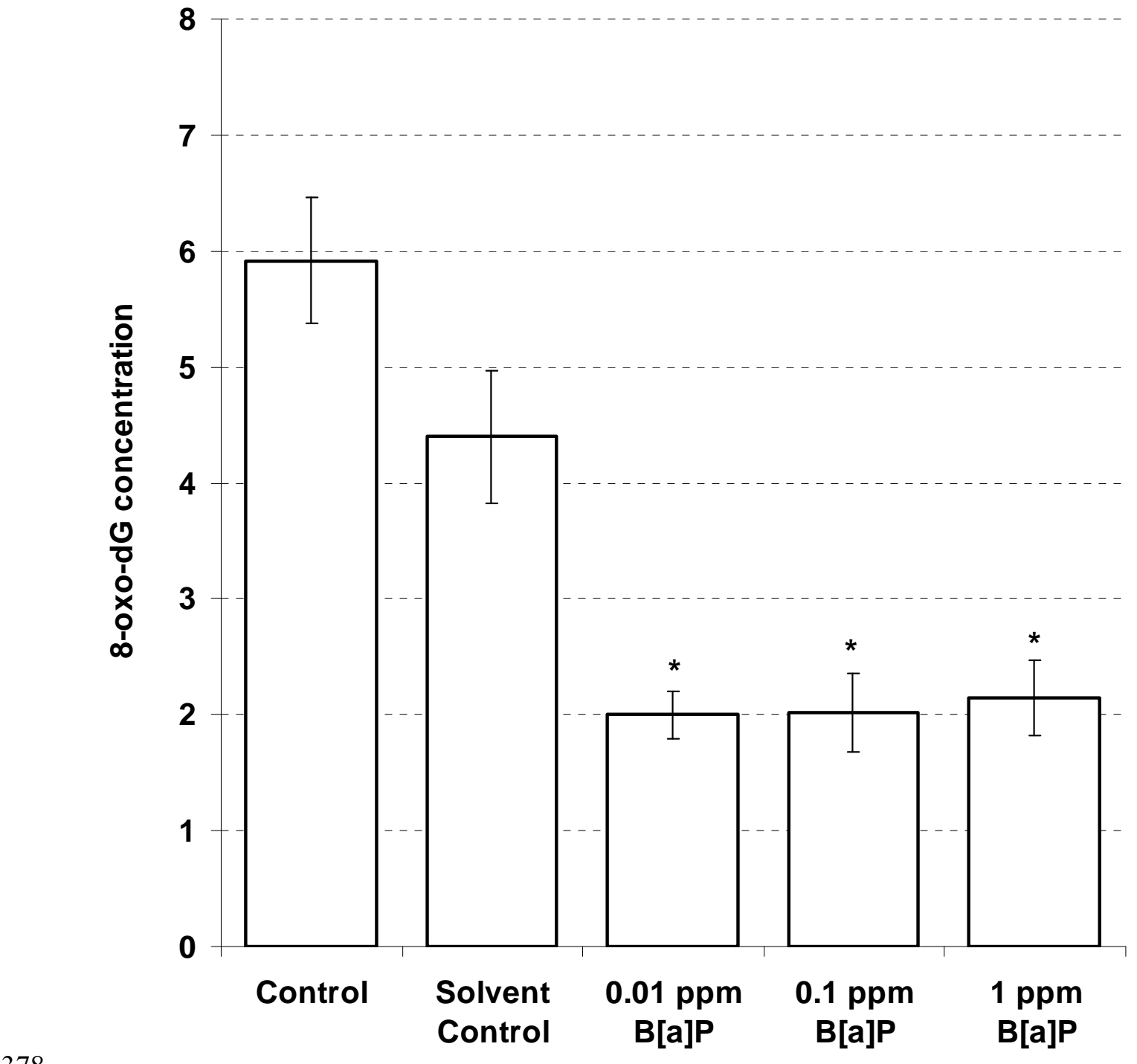

